\title{
幼儿园教师开展区域活动的问题与策略
}

\author{
黄宇晨
}

重庆市长寿区教师进修学校

DOI:10.32629/er.v2i11.2144

[ 摘 要] 区域活动是幼儿园日常教学活动的重要组成部分, 凸显以儿童为本的教育理念。本文探讨幼儿园教师在开展区域活动中存在的主要的 问题,进而从环境创设、活动中指导、活动后交流三个方面提出幼儿园教师开展区域活动的策略。

[关键词] 学前教育; 区域活动; 有效策略

区域活动是幼儿园日常教学活动的重要组成部分。《纲要》指出, 幼儿 是积极的活动者和主动的学习者。区域活动的正确开展符合以儿童为本的 教育理念, 凸显幼儿的主体性价值。区域活动强调幼儿的自由、自主和自 选活动, 因为这样有利于幼儿知识经验的建构和社会性的发展, 有利于提高 幼儿的认知能力, 以及提高幼儿发现问题、解决问题等自我学习的能力, 也 有利于幼儿创造性的自主表现。但是, 当前区域活动中, 还存在不少问题。

\section{1 区域活动存在的问题}

1. 1 教师对区域活动的认识有待清晰

区域活动中, 我们教师活动指导不到位, 其实主要是幼儿教师对区域 活动的认识不清晰, 将区域活动与小组教学活动混淆。区域活动中的教师 指导更多地应该通过材料实现 “隐形” 指导, 即使教师介入幼儿的活动, 也应该讲究策略, 不要太过于硬性干预。有些教师对区域活动指导的特殊 性缺乏认识, 往往把指导变成小组教学, 不是用活动的方式, 而是用小组教 学的方式组织活动, 既不能实现小组教学的目标, 也有违区域活动的自由、 自主、自选的本质特征, 无法实现真正的区域活动。

1.2 教师在活动中观察和研究意识有待加强

区域活动虽然强调幼儿的自主、自由, 但教师的作用依然重要, 教师要 成为幼儿区域活动的指导者, 达成区域活动的教育目标, 就需要对区域中 幼儿的活动情况进行细致的观察和研究, 对幼儿在活动中语言、行为、方 式等进行仔细的观察和研究。从而了解、发现幼儿的需求及兴趣, 了解幼 儿对材料的使用情况, 了解幼儿之间交往以及存在的问题, 以便进行适宜 的指导和以后区域环境的调整, 但我们常常发现不少幼儿老师缺乏观察研 究的意识或意识不强, 幼儿活动时, 老师并不仔细观察, 或有一定观察却没 有研究, 不能发现问题。

1. 3教师在活动中引导把控水平有待提高

不少教师对区域活动过程的把控不好, 常常出现两种极端现象, 一是 过于积极介入过程指导, 过多、过细地要求按照老师的想法去活动, 结果导 致对幼儿的活动干预过多、控制过多, 使区域活动丧失了对幼儿自主性发 展的重要价值。二是过于消极地完成过程指导, 可能是由于教师带班辛苦, 或认识不足, 到了区域活动时间, 便感觉终于可以喘口气休息一下, 使区域 活动时间成为了学生自己玩要活动的 “放羊时间”。无法实现区域活动的 教育目标。

1. 4 活动时间的科学性有待重视

区域活动的开展需要必要的时间保障, 但是不少的区域活动课时间使 用比较随意, 教师没有充分考虑幼儿的感受, 我们常常发现, 孩子们都还意 犹未尽或者没有完成活动, 老师却已经急着评价或者叫停活动。这样的活 动, 只是做了区域活动的形式, 不能为幼儿的发展创造一个真正自主探究 的环境, 难以达成区域活动的效果。

1. 5 活动后的交流分享作用有待进一步发挥
区域活动结束时的交流分享是区域活动教学的重要环节和内容, 却容 易被教师简单化处理成总结与表扬会。有些教师简单的理解为这个环节是 总结表扬时间——谁谁表现的好, 我们要像他学习, 谁表现的不够好, 出现 了什么问题, 下次注意等等。这种简单的处理不仅不能发挥这个环节应有 教育功能, 反而很容易让幼儿对区域活动产生反感心理。

\section{2 教师开展区域活动的有效策略}

2. 1 注重区域活动的环境创设

《纲要》指出, 环境是重要的教育资源。区域活动应提供良好的教育 环境, 促进幼儿的身心发展。因此区域活动环境的创设就是要满足各层次 幼儿的心理需求, 教师应通过环境的创设, 有效促进幼儿的发展。环境的创 设应遵循两个原则, 一是根据幼儿的认知特点、年龄特点、兴趣、季节及 教学活动开展情况来设置, 创设能够激发幼儿的探索兴趣, 引发幼儿主动 思考, 与幼儿产生互动的区域活动环境, 要能够充分发挥幼儿的主体作用。 二是环境的创设应以幼儿的生活经验、能力水平为基本条件, 根据幼儿的 生活经验, 创设与他经验相符合的游戏环境, 激发幼儿的游戏兴趣。

2.2 注重活动过程中的教师指导

2.2.1进入引导活动

在区域活动中, 最有效的指导策略就是教师参与幼儿的活动, 教师以 玩伴的身份指导幼儿的操作活动或游戏活动。教师通过参与幼儿活动来适 时指导, 不会给予幼儿压力和距离感, 又能更真切地感受和了解幼儿的想 法, 使指导更有针对性、有效性。指导的方式一是平行介入指导。教师和 幼儿一样, 平等地去玩区域里的玩具和材料, 不直接和幼儿发生交往活动, 即各玩各的。有时教师还可以边玩边自言自语。因为幼儿的模仿能力极强, 教师的玩法很容易成为幼儿模仿的对象, 从而引导幼儿的操作方式。一般 来说, 建构区、美工区、阅读区等区域活动都很适合教师采用平行介入的 方式引导幼儿的活动。二是交叉介入指导。教师作为角色的身份参与活动, 与幼儿共同游戏, 在游戏的情境中了解幼儿游戏的情况, 展开师幼互动, 引 导幼儿游戏的进展。教师参与角色, 可以根据活动的进展, 调整和引领活动, 提升活动的水平。

\subsection{2全程关注活动}

教师要更好地指导幼儿区域活动, 首先要时刻关注幼儿的活动, 准确 了解幼儿在活动中的需要和表现, 关注、了解幼儿已有的经验是什么, 了解 幼儿喜欢玩的是什么, 然后根据观察的情况, 在幼儿探索问题难以深入时, 发生纠纷、缺少材料、有破坏性行为等情况下, 教师才能及时给予指导。 如发现幼儿在活动中遇到困难时, 主动给予帮助、指导, 看到幼儿有破坏行 为给予纠正。

\subsection{3 适时介入活动}

教师在用心地观察幼儿活动, 就会发现很多问题, 这时需要教师及时 介入活动。在幼儿活动过程中, 当幼儿遇到困难玩不下去时, 当幼儿出现纠 


\section{中国推进国际关系民主化进程的解决方案}

郭旭

延边大学

DOI:10.32629/er.v2i11.2147

[摘要] “国际关系民主化”一直是世界各国探索与发展的一条主流趋势。本文联系目前中国的具体国情及发展现状,提出适合中国推动国际 关系民主化道路的可行性方案,以求不断建设和完善中国的新兴国际关系民主化,加快推动中国在国际关系民主化进程之中的发展。

[关键词] 中国; 国际关系; 民主化

时代在不断变化发展, 但国家与国家之间的关系依旧是国际体系的主 要宗旨与核心部分。国际关系民主化在其中扮演着举足轻重的关键角色, 关乎着国际社会的和平稳定与各国家的核心利益。现如今, 影响国际关系 的因素有很多, 在当今社会, 各国如何适应和融入到全球化的挑战之中, 是 需要各国必须解决的问题, 然而解决这个问题的主要方式, 就是国际关系 民主化。

\section{1 中国推进国际关系民主化进程的重要性}

“国际关系民主化” 概念首次提出是江泽民同志在《中非携手合作、 共迎新的世纪》讲话中提及并延续至今, 我国多位领导人在此后均有不同 程度的解读和阐释。党的十八大以来, 总书记继往开来、推陈出新地对于 国际关系民主化思想进行了丰富和创新, 主要内容包括四个方面: “政治上 主张世界的命运必须由各国人民共同掌握, 世界上的事情只能由各国政府 和人民共同商量来办”。 ${ }^{[1]}$ “经济上坚持互利共赢、共同发展, 既要让自己 过得好, 也要让别人过得好”。 ${ }^{[2]}$ “文化上尊重各种文明, 平等相待, 互学互 鉴, 兼收并蓄”。 ${ }^{[3]}$ “安全上倡导共同、综合、合作、可持续安全的理念, 尊重和保障每一个国家的安全。” ${ }^{[4]}$

世界《联合国宪章》中声明, 其中明确规定世界各国需要尊重国家主 权和领土完整, 同时不干涉内政。此规则也是国际关系民主化的基本原则 和底线。这 “有助于保证发展中国家的主权和独立性, 以及尊重世界各国 的领土主权和社会的基本的社会制度, 让每个国家都享有发展的权利, 不 可侵犯。” ${ }^{[5]}$

当今世界, “零和博弯” 与 “冷战思维” 的阴䨪还未完全消散殆尽, 虽然从一方面来看, 世界多极化制约了霸权主义和强权政治, 于国际关系
民主化大有裨益, 但全人类依然面临着恐怖主义、生态污染、国际犯罪活 动猖獗、人口膨胀、毒品泛滥、贫困失业、疾病流行、国际信息安全等全 球性挑战。“面对前所未有的挑战, 没有任何一个国家可以独善其身” ${ }^{[6]}$, 任何一个国家都不能置身事外, 世界各国理应通力合作, 建立一种利于国 际协调与控制的民主化体系, 从客观上实现国际关系民主化。

\section{2 中国推进国际关系民主化的方案}

“当今我国民主化的推进受很多的因素影响, 也面临着太多的阻碍, 但是, 随着时代的发展和全球化的影响, 国际关系民主化的趋势不可逆转。 因而, 世界各国应该积极制定民主化发展的策略, 有了明确的规划, 才有前 进的方向, 国际关系民主化需要各个国家的共同努力。” ${ }^{[7]}$ 我国目前具备民 主化的各项条件, 但是国际关系民主化还需要不断地努力, 还有很长的路 要走。

国际关系中国家与国家间的亲疏冷暖实质是国际利益导致的冲突与 合作, 不论是国家行为主体还是非国家行为主体, 都是为了追逐自己的利 益诉求, 这就不可避免的会产生激烈的竞争。当前经济竞争尤为激烈, 国际 关系民主化的一方面是各个国家友好的经贸往来, 但是在世界的大舞台, 发达国家的整体实力占有重要的优势, 竞争中处于有利地位。

随着我国十九大的胜利召开, 总书记对国际关系民主化的战略构想进 行了重述与创新, “中国秉持共商共建共享的全球治理观, 倡导国际关系民 主化, 坚持国家不分大小、强弱、贫富一律平等, 支持联合国发挥积极作用, 支持扩大发展中国家在国际事务中的代表性和发言权。中国将继续发挥负 责任大国作用, 积极参与全球治理体系改革和建设, 不断贡献中国智慧和 力量。” ${ }^{[8]}$ 践行价值既有利于国内政治体制的良性发展, 又有利于世界各
纷与行为问题时, 当游戏无法深入时, 当孩子操作发生困难时及时介入, 教 师进京及时介入活动, 给予指导。保证活动顺利进行, 完成活动目标。

\section{3 注重区域活动后的交流分享}

3. 1 作品展示

教师可让孩子去不同的区域参观幼儿的作品, 鼓励幼儿相互交流, 学 习分享。教师也可以把部分幼儿的作品拍下来, 通过屏幕的方式共同欣赏。 在这个过程中鼓励幼儿大胆的表达自己的见解, 同时培养幼儿的倾听能力, 并学习别人的经验, 提升自己的能力。

3. 2 问题讨论

区域活动中出现的问题具有一定的普通性, 如角色扮演的问题、材料 的使用、创新问题, 规则的遵守问题等等, 教师可给予时间让幼儿去讨论。 通过讨论, 引导幼儿学习解决问题的方法, 提升幼儿自我管理的能力和学 习能力。

\section{4 结束语}

区域活动已经成为幼儿园不可缺少的活动, 要让区域活动实现促进幼
儿发展的价值, 不管是环境的创设、活动的设计, 还是活动中指导、活动后 的交流评价都需要幼儿教师的智慧。作为教师, 要不断实践, 探索, 积累经 验, 从孩子的兴趣出发, 尊重孩子, 充分调动孩子的积极性, 使区域活动更 具科学性、有效性, 充分利用区域活动这一平台, 促进幼儿心智和社会交往 的发展。

\section{[参考文摘]}

[1]郭迪.中班区域活动师幼互动中幼儿发起者的特点及思考 [ J . 才 智, 2017(27):173.

[2]侯龙龙. 幼儿园区域活动中的师幼互动研究 [J]. 课程教育研 究,2016(01):13-14.

[3]冯晓霞.构建 21 世纪的中国幼儿园课程一一幼儿主体性发展课程 思考[J].教育科学研究,1999(01):57-64.

\section{作者简介:}

黄宇晨(1982--), 女, 重庆长寿人, 汉族, 本科, 讲师, 研究方向: 教师 培训、学前教育; 从事工作: 教师。 